\title{
Rare Occurrence: Exploring loT, news media, calm interfaces and infrequent interactions
}

\author{
John Mills \\ Media Innovation Studio \\ UCLan \\ jmills@uclan.ac.uk
}

\author{
Tom Metcalfe \\ Thomas Buchanan \\ Bristol \\ tom@thomasbuchanan.eu
}

\author{
Mark Lochrie \\ Media Innovation Studio \\ UCLan \\ mlochrie@uclan.ac.uk
}

\author{
Adrian Gradinar \\ LICA \\ Lancaster University \\ a.gradinar@lancaster.ac.uk
}

\begin{abstract}
Positioned as a new digital interaction paradigm and the potential realisation of ubiquitous computing, the 'Internet of Things' is associated with ever-widening user-experiences, products and industries. It is rapidly entering the public consciousness. Spanning smart cars, connected toys, cheap 'maker' components and sensor-driven smart cities, loT casts a wide cloak over nearfuture digital evolution and Human-Computer Interaction. But what about stories? Our research focuses on a novel design approach to news and media loT devices. If storytelling is embedded in objects, what opportunities lay beyond the confines of the screen? Can the 'white noise' of digital news be inverted through infrequent and rarely occurring interactions with media via calm interfaces and ambient technologies? This paper considers if 'Rare Occurrence' objects create novel user connections with deconstructed editorial content and describes objects that communicate news or media that happens rarely, and in doing so seek to create meaning and editorial engagement.
\end{abstract}

Internet of Things. News Media. Calm Interfaces. Ambient technologies. Interaction. Design.

\section{INTRODUCTION}

Since the first forays into the digital realm, the news media has been in a position of playing catch-up. Its century-old business models, which revolved around its platform (newsprint, television or radio) placing advertising in front of captive audiences, and inviting the audience themselves to pay for this access, have been disrupted by the transition of advertising revenue and audience to digital platforms (Picard) such as Google, Facebook and Craigslist (Kaiser; Seamans and Zhu). National, international and local publishers have rationalised their businesses, cut jobs (Doctor) or folded under the weight of challenging market conditions (Guardian, 2016). Readers of traditional newspapers are falling (Guardian, 2015), and television viewing habits are in flux due to influence of digital portals. Among radio, television and newsprint, it is perhaps only audio that is weathering the storm. In the last decade, a number of publishers, public bodies and independent citizens have sought to innovate journalism in light of these changing social and market conditions (Castells; Shirky; Arrese), and embrace digital media through trialling new commercial models and approaches. Nevertheless, progress has been mixed, with digital platforms continually presenting new challenges that have impacted on traditional newsrooms in terms of their profitability, production and ultimately position within the media ecosystem.

This industry malaise is set against a potentially new digital expansion in the Internet of Things (IoT) (Sundmaeke et al), but one that is at an embryonic stage (Serbanati). Connected objects could create a new range of affordances and user experiences (Kranenburg et al). Studies show that loT has huge growth potential. Consultancy McKinsey (Bauer) suggests that by 2020 there could be between $26 \mathrm{bn}$ and 30bn "connected devices", which represent year-on-year growth of between 15 and $20 \%$, and Cisco place total devices at $40 \mathrm{bn}$ by 2019 (Castillo and Thierer). Data activations from these devices continue apace - in 2014 Verizon saw $135 \%$ revenue growth from US 4GLTE IoT connectivity (Verizon). IoT innovation is also coming from the 'ground up' as affordable devices such as Arduinos, open source communities and accessible, home-based 3D-printing options are fuelling grassroots 'making'.

Amid this rapid adoption, and in light of challenges faced by the news media in meeting commercial and audience digital demands, IOT potentially presents the sector with a new communications paradigm. The challenge for media publishers, product designers, technologists and humancomputer interaction specialists is to create loT experiences and objects that convey editorial in 
meaningful ways. Our formative research explores how calm technology (Weiser et al.) and screenfree objects could be used by both publishers and audiences, and begins to explore how narratives can be deconstructed to enable object-based publication.

\section{BACKGROUND AND FORMATIVE WORK}

Our early research focused on creating internetconnected interactive printed surfaces via conductive ink matrices. Substrates could detect human touch and the prototypes aligned a media experience to the static print layouts (Mills). Media was dynamic as researchers could update content remotely and continually due to a cloud-based infrastructure that underpinned the physical experience. This incorporated a mobile app and content management/analytics suite. The co-design process with industry representatives, content generators and audiences, revealed that digital media, when represented via a physical object, presented challenges to the design and interaction of both content and 'thing'. A further factor was how screen-free digital objects handled the 'white noise' of digital content. In light of tools that filter and aggregate, or perform a multifaceted dashboard function (Tweetdeck), how can users navigate large volumes of instant and constantly updated media?

\section{RARE OCCURRENCE: CALM, AMBIENT AND INFREQUENT MEDIA INTERACTIONS}

Our research adopts a content and design approach that is a counterpoint to the always-on, constantly-connected reality of news and information in the digital age. In designing news media loT objects, our prototypes explore our relationships with internet-connected objects that may not deliver media content upon each and every interaction. Informed by our previous research and industry work, our approach explores internet-connected objects that are built upon technology that is inconspicuous, unobtrusive and ambient (Wikipedia; Rowland et al). For Rare Occurrence it was fundamental that objects weren't 'shouting' for user attention, and this required a design approach that understood user behaviour and routine, and establishing how a new type of object would fit with this.

The family of Rare Occurrence has begun to answer these questions. They explore simple yet unfamiliar interactions that require little learning but provoke new reactions and emotions from the user. The object aesthetic is simple, as is the animation and behaviour of the anthropomorphic character.

Running side-by-side with the interface development, we also explore how content can be adapted. This approach focusses on two distinct areas: offer control for navigating content to users (and thus subverting the more traditional 'push' of traditional media). One approach is to invert this push, to pull, and allow loT devices to transmit media that is only focussed and relevant to the user. Based on predefined criteria that allow the object to function in the 'background', its only interaction is to activate content. An alternative approach is to deconstruct news and information to raw component parts, and use objects to convey a meaning or message. For example, an object's interactivity (via a movement or other signifier) would not have meaning unless a user was aware of the object's role, purpose and functionality.

\subsection{Objects}

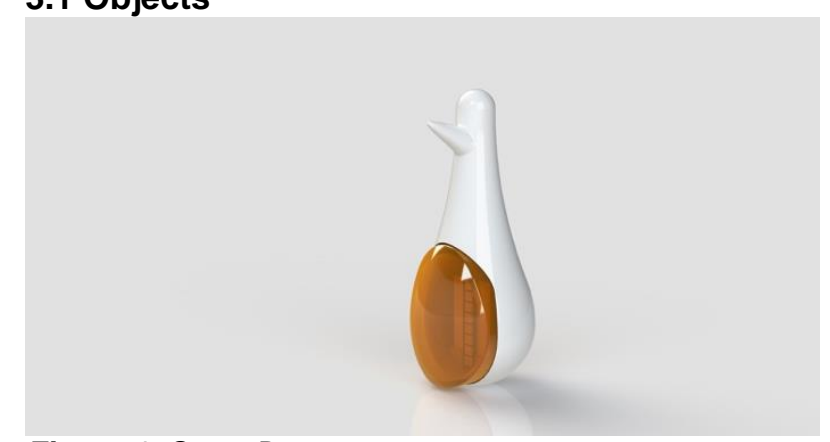

Figure 1: Snow Day

So far, the Rare Occurrence methodology has been used to create two objects that convey news media in varying degrees of deconstruction.

Infrequency: An internet-connected radio. By nudging the side of the radio, a user plays a podcast from a predefined genre.

Snow Day: A connected children's toy in the form of a penguin. When picked up, its tummy glows, and the child knows that school is closed. In adopting an open source approach, building Snow Day can be integrated into a school's curriculum.

\subsection{Underpinning infrastructure}

Another layer of development is the 'Interface' cloud platform Content Management System (CMS) and analytics suite. Cloud platforms for loT are essential in the customisation and personalisation of home-based devices, and Interface permits users to populate devices with content. For example, Snow Day users can specify a Twitter account and/or hashtags they wish to receive updates from. Resulting object analytics are based around common themes and thingspecific insights. In using Twitter, Snow Day also unites disparate national approaches to informing children of school closures.

\section{Future work: challenges and approaches}

The research team plan future iterations of Rare Occurrence objects co-designed with industry, 
individual content generators and audience/users. Iterated prototypes will be deployed in user homes and workplaces over extended timeframes, and be assessed through both qualitative data and quantitative usage data (generated by Interface). Considering the rapidly-developing loT market and associated R\&D, we hope to create minimum viable products via an agile methodology of product iteration and continuing user engagement.

\section{REFERENCES}

Arrese, Á. (2015). From Gratis to Paywalls: A brief history of a retro-innovation in the press's business. Journalism Studies 1-17. DOI: 10.1080/1461670X.2015.1027788

Bauer, H., Patel, M., Vera, J., (2014), The Internet of Things: Sizing Up the Opportunity, Mclnsey, http://www.mckinsey.com/industries/hightech/our-insights/the-internet-of-things-sizing-upthe-opportunity. (1 March 2016).

Kaiser, R.,G., The Bad News about News, available from http://www.brookings.edu/research/essays/2014/ bad-news\#. (3 March 2016)

Castells, M. (2011). The Rise of the Network Society: The Information age: Economy, Society, and Culture (Vol. 1). John Wiley \& Sons.

Castillo, A., Thierer, A.D. (2015) Projecting the Growth and Economic Impact of the Internet of Things. Available at SSRN 2618794.

Doctor, K., (2015), Newsonomics: The halving of America's Daily Newsrooms, Nieman Lab, available from http://www.niemanlab.org/2015/07/newsonomics -the-halving-of-americas-daily-newsrooms/. March 2016).

Doyle, G. (2013). Understanding Media Economics. SAGE Publications Limited.

Van Kranenburg, R., Anzelmo, E., Bassi, A., Caprio, D., Dodson, S., \& Ratto, M. (2011). The Internet of things. A critique of ambient technology and the all-seeing network of RFID, Network Notebooks, 2.

Guardian, (2015), National daily newspaper sales fall by half a million in a year, available from http://www.theguardian.com/media/2015/apr/10/ national-daily-newspapers-lose-more-than-halfa-million-readers-in-past-year. ( 3March 2016).

Guardian, (2016), Newspaper Closures, available from http://www.theguardian.com/media/newspaperclosures. (1 March 2016).
Mills, J., Lochrie, M., Dickinson, A., Metcalfe, T., \& Egglestone, P. (2015, November). Connected Paper, EKKO and Analytic Futures: News and Paper Data. In Proceedings of the 2015 International Conference on Interactive Tabletops \& Surfaces, Madeira, November $15^{\text {th }}$ $18^{\text {th }}$, ACM. 253-258.

Rowland, C., Goodman, E., Charlier, M., Light, A., \& Lui, A. (2015). Designing Connected Products: UX for the Consumer Internet of Things. O'Reilly Media, Inc.

Seamans, R; Zhu, F., (2014). Responses to Entry in Multi-Sided Markets: The Impact of Craigslist on Local Newspapers. Management Science 60 (2): 476-493.

Serbanati, A., Medaglia, C. M., \& Ceipidor, U. B. (2011). Building blocks of the internet of things: State of the art and beyond. INTECH Open Access Publisher.

Shirky, C. (2009). Here Comes Everybody: How change happens when people come together. Penguin UK.

Sundmaeker, H., Guillemin, P., Friess, P., \& Woelfflé, S. (2010). Vision and challenges for realising the Internet of Things. CERP-IOT Cluster of European Research Projects on the Internet of Things.

Tweetdeck, available from https://about.twitter.com/products/tweetdeck. (8 June 2016).

Verizon, (2015), State of the Market: The Internet of Things 2015, available from http://www.verizonenterprise.com/resources/rep orts/rp_state-of-market-the-market-the-internetof-things-2015_en_xg.pdf. (1 March 2016).

Weiser, M., \& Brown, J. S. (1996). Designing calm technology. PowerGrid Journal, 1(1), 75-85.

Wikipedia, available from https://en.wikipedia.org/wiki/David_L._Rose. 1 June 2016). 